\title{
Influence of p38MAPK inhibition on IL-1B-stimulated human chondrocytes: A microarray approach
}

\author{
HELGA JOOS $^{1}$, WOLFGANG ALBRECHT ${ }^{2}$, STEFAN LAUFER $^{3}$ and ROLF E. BRENNER ${ }^{1}$ \\ ${ }^{1}$ Division for Biochemistry of Joint and Connective Tissue Diseases, Department of Orthopedics, \\ University of Ulm, Ulm; ${ }^{2}$ Department of Chemical Drug Research, Ratiopharm GmbH, Ulm; \\ ${ }^{3}$ Institute of Pharmacy, Department of Pharmaceutical and Medicinal Chemistry, \\ Eberhard Karls University Tübingen, Tübingen, Germany
}

Received December 4, 2008; Accepted February 9, 2009

DOI: 10.3892/ijmm_00000181

\begin{abstract}
Articular chondrocytes respond to extracellular influences by activating signaling pathways which change gene expression. One key signal transduction pathway of inflammatory joint disease is mediated by the p38MAPK which is known to be activated by the pro-inflammatory cytokine IL-1ß. We used the p38MAPK inhibitor SB203580 and a whole human genome microarray in an in vitro inflammation model to identify genes regulated by this pathway in human chondrocytes. We found that 1,141 genes were regulated by IL-1ß, and 646 genes were regulated by the inhibitor whereas 116 genes were co-regulated by both substances. To elucidate the overall effect of SB203580, a GoMiner pathway analysis was performed which revealed involvement of versatile biological processes. Predominantly affected terms were 'response to stimulus', 'oxygen metabolism' and 'ligase activity'. We discuss herein the relevance and function of affected fields including the involved genes and unexpected effects of p38MAPK inhibition as it relates to the context of cartilage. Our results do not predict a pro-apoptotic or cancer promoting effect and markedly extend the knowledge on p38MAPK inhibition in chondrocytes beyond primary target genes.
\end{abstract}

\section{Introduction}

In arthritis, signaling pathways are induced by mechanical stress and/or inflammatory cytokines (1). An important mediator of inflammation in rheumatoid and osteoarthritis is the cytokine IL-1ß which is tightly associated with joint destruction, e.g. by inducing cartilage-degrading enzymes or

Correspondence to: Dr Rolf E. Brenner, Division for Biochemistry of Joint and Connective Tissue Diseases, Department of Orthopedics, University of Ulm, Ulm, Germany

E-mail: rolf.brenner@uni-ulm.de

Key words: IL-1ß, chondrocytes, arthritis, p38MAPK, SB203580, microarray, GoMiner analysis further pro-inflammatory factors (2). One of the involved signaling pathways is the p38MAPK pathway, a complex cascade of protein kinases that mediates multiple functions including cytokine production and cell death. The family of p38MAPK at the center of the pathway is composed of $\alpha, \beta, \gamma$ and $\delta$ isoforms. The ubiquitously expressed $\alpha$ and $\beta 2$ forms are key enzymes in inflammatory signaling (3). The MAPK p38 $\alpha$ transduces signals through downstream effectors such as transcription factors, elongation factors, and other MAPKs. It contributes to inducible cytokine gene expression at least partially by stabilizing mRNA (3). This kinase represents a point of convergence for multiple signaling processes which impact on a broad range of inflammatory events. The p38MAPK is therefore a prime target for the development of anti-inflammatory drugs. By now, diverse inhibitors have been identified. The pyridinyl imidazole inhibitor SB203580 was reported on in 1994 (4) and is often used as a reference p38 inhibitor. It is equipotent against p38 $\alpha$ and p38ß, binds competitively with respect to ATP and inhibits the kinase activity of the activated and unactivated forms of the kinase (3). Numerous studies implicated p38MAPK inhibition, and its efficacy was demonstrated in a variety of models for selected aspects of cellular response. A comprehensive knowledge of genome-wide effects on gene expression and cell metabolism, however, has not yet been achieved. As the p38MAPK has a key function in cell signaling, a broad approach could shed light on the versatile effects of p38MAPK inhibition. Recently, Namdari et al reported on transgenic mice with reduced p38MAPK activity in chondrocytes showing higher grades of osteoarthritis in the knee joint (5). This finding clearly demonstrates the need for further investigations on cellular effects beyond well-known target genes. We, therefore, conducted a whole human genome array analysis to identify further downstream genomic targets of p38MAPK inhibition possibly relevant for therapeutic application in an established inflammation cell culture model using IL-1ß-stimulated human chondrocytes.

\section{Materials and methods}

Cartilage samples. Human osteoarthritic cartilage was obtained from 18 donors undergoing total knee replacement 
due to osteoarthritis with informed consent of the patients according to the terms of the Ethics Committee of the University of Ulm. The age of the donors ranged from 58 to 72 years.

Cell culture. Well-preserved cartilage from femoral condyles was used for chondrocyte isolation as described previously (6). The cartilage was minced and digested 45 min with $9 \mathrm{U} /$ $\mathrm{ml}$ pronase (Sigma-Aldrich, Munich, Germany) and $14 \mathrm{~h}$ with $80 \mathrm{U} / \mathrm{ml}$ collagenase (Sigma). After washing and filtering, the isolated cells were cultivated in complete medium consisting of 1:1 DMEM/Ham's F12 supplemented with 10\% fetal bovine serum, $0.5 \%$ penicillin/streptomycin, $0.5 \%$ L-glutamine and $10 \mu \mathrm{g} / \mathrm{ml}$ 2-phospho-L-ascorbic acid trisodium salt (Sigma-Aldrich, Fluka, Seelze, Germany). After $24 \mathrm{~h}$ of incubation, adhered chondrocytes were frozen in complete medium containing 5\% DMSO (dimethyl sulfoxide; Roth, Karlsruhe, Germany). All chemicals were obtained from Biochrom, Berlin, Germany, unless indicated otherwise.

Cell stimulation and treatment with p38MAPK inhibitor. After thawing and recovering in complete medium, cells of 6 different donors were pooled and seeded at a density of $5 \times 10^{4}$ cells $/ \mathrm{cm}^{2}$. After $24 \mathrm{~h}$ of adherence in complete medium, cells were silenced for $24 \mathrm{~h}$ in serum-free medium (DMEM containing $0.5 \%$ penicillin/streptomycin, $0.5 \%$ L-glutamine, $1 \%$ non-essential amino acids 100 -fold concentrate, $1 \mathrm{mM}$ Pyruvat, $0.1 \%$ SES1 Solution A and $0.1 \%$ freshly added SES1 Solution B (all from Biochrom). Subsequently, cells were stimulated for $24 \mathrm{~h}$ with $10 \mathrm{ng} / \mathrm{ml} \mathrm{rhIL}-1 \beta$ (tebu-bio, Offenbach, Germany) in serum-free medium, and inhibitortreated cells were pre- (15 min) and co-incubated with $10 \mu \mathrm{M}$ SB203580 (provided by RPatiopharm GmbH, Ulm, Germany) in addition to stimulation. Cells were lysed in 600 $\mu 1$ lysis buffer RLT (Qiagen, Hilden, Germany) per $10^{6}$ cells.

Microarray. After cell lysis, a whole human genome oligomicroarray (Human Genome Oligo Set Version 2.0, Operon, Germany) was conducted at the Chip Facility of Ulm according to Buchholz et al (7). All experiments were performed in triplicate with 6 different donors each. The hybridization signals were analyzed with GenePix Pro 4.0 imaging software (Axon Instruments, Union City, CA, USA). Data normalization was performed with the LIMMA software package.

GOMiner analysis. Genes which showed at least a 2-fold regulation and a significance level of $\mathrm{p}<0.05$ in the microarray analysis were assigned to Gene Ontologies by a pathway analyzing tool called GoMiner $(8,9)$. We used the three ontologies produced by the Gene Ontology (GO) consortium, namely 'biological process', 'cellular component' and 'molecular function'. In brief, given a set of genes and one ontology, the set of all unique GO terms within the ontology were first identified which were associated with one or more of the genes of interest. Next, the number of selected differentially expressed genes and the number of genes that were assayed (all the genes represented on the microarray) were annotated at each term (8).
mRNA isolation. mRNA was isolated with the RNeasy Mini Kit (Qiagen) in accordance with the manufacturer's instructions.

Statistical analysis. For the microarray results, a Print-tip LOESS-normalization according to Buchholz et al (7) and a moderated t-test (10) were performed at the Chip Facility of Ulm. In the GoMiner analysis, the two-sided Fisher's exact test evaluated whether there were more genes of interest at the term than one might expect by chance (8).

\section{Results}

To understand the molecular basis of osteoarthritis (OA) cartilage degeneration and to develop novel approaches to therapeutic options, a thorough knowledge of the involved cell-biological processes is important. The p38MAPK, a key enzyme in pathway signaling, represents a promising pharmaceutical target. Therefore, we investigated the effects of the p38MAPK inhibitor SB203580 in an in vitro OA model using a microarray approach.

Cell phenotype and viability. For the microarray experiment, OA cartilage was used which macroscopically had a smooth surface and no severe osteoarthritic changes. As described elsewhere (6), the chondrocytes showed a stable differentiation stage during the experimental period and comparable cell viability with and without IL-1ß-stimulation.

Microarray experiment. Our whole human genome microarray represented $\sim 23,000$ genes. Genes were defined as differentially expressed between the probe and associated reference if first, the difference between the mean normalized expression values was at least 2-fold between the sample sets and second, a two-sided t-test yielded a p-value $<0.05$. All of the microarray data have been deposited on ArrayExpress (http:// www.ebi. ac.uk/microarray-as/aer; Accession no. E-MEXP-1434).

Chondrocyte treatment with IL-1B and the p38MAPK inhibitor SB203580 induced numerous changes in the chondrocyte gene expression profile. Overall, 1,141 genes were regulated by IL-1ß compared to control cells. Coincubation of IL-1ß-stimulated cells with SB203580 revealed a total of 646 genes regulated by SB203580 compared to cells treated with IL-1ß but not inhibited. By comparison of IL-1ß- and SB203580-regulated genes, we found 116 common genes that were co-regulated by both treatments. Most of the co-modulated genes were regulated in opposite directions; only $13 \%$ moved unidirectional and from these most genes were up-regulated. Among the analyzed genes of the microarray, some are hypothetical or unknown (42 of the 116 coregulated genes). The intersections of the number of all IL-1ßand SB203580-regulated genes and the list of known coregulated genes with their accession numbers, fold change and p-values for both IL-1ß and SB203580 regulation are shown in Fig. 1 and Table I.

GoMiner analysis of co-regulated genes. Genes co-regulated by IL-1ß and SB203580 were further analyzed with the GoMiner software tool and classified into biological coherent categories. A Fisher's exact test evaluated Gene ontology 
Table I. List of genes co-regulated by IL-1ß and SB203580 in human chondrocytes.

\begin{tabular}{|c|c|c|c|c|c|c|}
\hline \multirow[t]{2}{*}{ Gene symbol } & \multirow[t]{2}{*}{ Gene description } & \multirow{2}{*}{$\begin{array}{c}\text { Gene Bank } \\
\text { Accession no. }\end{array}$} & \multicolumn{2}{|c|}{ Influence of IL-1ß } & \multicolumn{2}{|c|}{ Influence of SB203580 } \\
\hline & & & Fold change & p-value & Fold change & p-value \\
\hline \multicolumn{7}{|c|}{ Down-regulated by IL-1ß } \\
\hline HOMER-3 & Homer, neuronal immediate early gene, 3 & NM_004838 & 0.071 & 0.0043 & 3.701 & 0.0147 \\
\hline HOXD12 & Homeo box D12 & NM_021193 & 0.122 & 0.0003 & 3.292 & 0.0459 \\
\hline SHARP & SMART/HDAC1 assoc. repressor protein & NM_015001 & 0.168 & 0.0051 & 3.391 & 0.0349 \\
\hline EEF1A1 & Eukar. translation elongation factor $1 \alpha 1$ & AJ420488 & 0.183 & 0.0009 & 0.478 & 0.0413 \\
\hline TUBB & Tubulin, B polypeptide & NM_001069 & 0.187 & 0.0000 & 3.213 & 0.0136 \\
\hline FKBP9 & FK506 binding protein 9 (63 kDa) & ВC011872 & 0.215 & 0.0040 & 2.077 & 0.0245 \\
\hline CPSF1 & $\begin{array}{l}\text { Cleavage and polyadenylation } \\
\text { specific factor } 1,160 \mathrm{kDa} \text { subunit }\end{array}$ & NM_013291 & 0.239 & 0.0029 & 6.449 & 0.0137 \\
\hline PDCD2 & Programmed cell death 2 & AK055180 & 0.242 & 0.0321 & 10.112 & 0.0297 \\
\hline LETM1 & $\begin{array}{l}\text { Leucine zipper-EF-hand containing } \\
\text { transmembrane protein } 1\end{array}$ & NM_012318 & 0.249 & 0.0004 & 2.138 & 0.0138 \\
\hline GSTA4 & Glutathione S-transferase A4 & NM_001512 & 0.290 & 0.0246 & 7.268 & 0.0043 \\
\hline RPL18 & Ribosomal protein L18 & NM_000979 & 0.295 & 0.0304 & 2.046 & 0.0439 \\
\hline TRIM36 & Tripartite motif-containing 36 & NM_018700 & 0.303 & 0.0452 & 3.795 & 0.0188 \\
\hline BARX1 & BarH-like homeobox 1 & NM_021570 & 0.309 & 0.0003 & 2.867 & 0.0263 \\
\hline RAB27A & RAB27A, member RAS oncogene family & U38654 & 0.309 & 0.0173 & 3.543 & 0.0101 \\
\hline MT-ACT48 & Mitochondrial acyl-CoA thioesterase & NM_012332 & 0.336 & 0.0328 & 4.660 & 0.0045 \\
\hline PDLIM1 & PDZ and LIM domain 1 (elfin) & NM_020992 & 0.355 & 0.0253 & 2.228 & 0.0280 \\
\hline MKKS & McKusick-Kaufman syndrome & NM_018848 & 0.387 & 0.0051 & 4.347 & 0.0055 \\
\hline HDAC8 & Histone deacetylase 8 & NM_018486 & 0.394 & 0.0012 & 2.021 & 0.0183 \\
\hline LASP1 & LIM and SH3 protein 1 & NM_006148 & 0.408 & 0.0007 & 2.328 & 0.0180 \\
\hline EVC & Ellis van Creveld syndrome & NM_014556 & 0.422 & 0.0018 & 2.158 & 0.0107 \\
\hline NARS & Asparaginyl-tRNA synthetase & NM_004539 & 0.423 & 0.0023 & 2.143 & 0.0184 \\
\hline ANXA2P3 & Annexin A2 pseudogene 3 & M62895 & 0.428 & 0.0063 & 2.735 & 0.0222 \\
\hline C2orf9 & Chromosome 2 open reading frame 9 & NM_032309 & 0.434 & 0.0116 & 9.320 & 0.0015 \\
\hline CCT6A & Chaperonin contain. TCP1, subunit $6 \mathrm{~A} \zeta 1$ & NM_001762 & 0.439 & 0.0177 & 3.094 & 0.0299 \\
\hline HYA22 & HYA22 protein & NM_005808 & 0.451 & 0.0018 & 3.328 & 0.0343 \\
\hline TPST1 & Tyrosylprotein sulfotransferase 1 & NM_003596 & 0.458 & 0.0332 & 2.304 & 0.0332 \\
\hline LOC51031 & CGI-150 protein & NM_016080 & 0.475 & 0.0042 & 2.823 & 0.0097 \\
\hline TR (PRDX2) & Thioredoxin peroxidase reductase & NM_005809 & 0.487 & 0.0029 & 2.179 & 0.0407 \\
\hline NYD-SP27 & Testis-development related NYD-SP27 & NM_033123 & 0.488 & 0.0285 & 2.521 & 0.0252 \\
\hline GPR58 & G protein-coupled receptor 58 & NM_014626 & 0.494 & 0.0333 & 2.364 & 0.0365 \\
\hline
\end{tabular}

Up-regulated by IL-1ß

$\begin{array}{lllrrrr}\text { SOD2 } & \text { Superoxide dismutase 2, mitochondrial } & \text { NM_000636 } & 74.988 & 0.0000 & 0.329 & 0.0276 \\ \text { MMP13 } & \text { Matrix metalloproteinase 13 (collagenase 3) } & \text { NM_002427 } & 67.185 & 0.0008 & 0.074 & 0.0003 \\ \text { RAB5C } & \text { RAB5C, member RAS oncogene family } & \text { NM_004583 } & 26.556 & 0.0000 & 0.042 & 0.0014 \\ \text { NOS2A } & \text { Nitric oxide synthase 2A (induc., hepatoc.) } & \text { NM_000625 } & 23.638 & 0.0022 & 0.182 & 0.0027 \\ \text { SLC9A3R1 } & \text { Solute carrier family 9 (sodium/hydrogen } & \text { NM_004252 } & 16.833 & 0.0042 & 0.135 & 0.0127 \\ \text { KRTHA7 } & \text { Keratin, hair, acidic, 7 exchanger, } & \text { NM_003770 } & 16.807 & 0.0036 & 0.194 & 0.0151 \\ & \text { isoform 3 reg. factor 1 } & & & & 0.079 & 0.0279 \\ \text { GBP1 } & \text { Guanylate binding protein 1, } & \text { NM_002053 } & 14.361 & 0.0000 & & \\ & \text { interferon-inducible, 67 kDa } & \text { NM_016582 } & 13.125 & 0.0000 & 0.232 & 0.0104 \\ \text { PHT2 } & \text { Peptide transporter 3 } & \text { NM_005373 } & 9.517 & 0.0006 & 0.209 & 0.0082 \\ \text { MPL } & \text { Myeloproliferative leukemia virus oncogene } & \text { Nar } & \\ \text { HLA-A } & \text { Major histocompatibility complex, class I, A } & \text { NM_002116 } & 8.587 & 0.0002 & 0.301 & 0.0030 \\ \text { HUMMHCW1A } & \text { Cw1 antigen } & \text { M12679 } & 8.171 & 0.0150 & 0.294 & 0.0259 \\ \text { NUP160 } & \text { Nucleoporin 160 kDa } & \text { D83781 } & 7.291 & 0.0031 & 0.207 & 0.0049 \\ \text { G1P3 } & \text { Interferon, } \alpha \text {-inducible prot. (clone IFI-6-16) } & \text { NM_022873 } & 6.541 & 0.0169 & 0.444 & 0.0398 \\ \text { ITGB3BP } & \text { Integrin B 3 binding prot. (B3-endonexin) } & \text { NM_014288 } & 6.144 & 0.0369 & 2.262 & 0.0195 \\ \text { PLIN } & \text { Perilipin } & \text { NM_002666 } & 4.766 & 0.0032 & 2.448 & 0.0191\end{array}$


Table I. Continued.

\begin{tabular}{|c|c|c|c|c|c|c|}
\hline \multirow[t]{2}{*}{ Gene symbol } & \multirow[t]{2}{*}{ Gene description } & \multirow{2}{*}{$\begin{array}{c}\text { Gene Bank } \\
\text { Accession no. }\end{array}$} & \multicolumn{2}{|c|}{ Influence of IL- $1 ß$} & \multicolumn{2}{|c|}{ Influence of SB203580 } \\
\hline & & & Fold change & p-value & Fold change & p-value \\
\hline SF3B3 & Splicing factor $3 \mathrm{~b}$, subunit $3,130 \mathrm{kDa}$ & NM_012426 & 4.477 & 0.0465 & 2.462 & 0.0233 \\
\hline WARS & Tryptophanyl-tRNA synthetase & NM_004184 & 4.379 & 0.0097 & 0.365 & 0.0342 \\
\hline ITGA2B & $\begin{array}{l}\text { Integrin, } \alpha 2 \mathrm{~b} \text { (platelet glycoprotein } \\
\text { IIb of IIb/IIIa complex, antigen CD41B) }\end{array}$ & NM_000419 & 4.028 & 0.0009 & 0.319 & 0.0265 \\
\hline GRIK5 & Glutamate receptor, ionotropic, kainate 5 & AJ249209 & 3.989 & 0.0010 & 0.463 & 0.0360 \\
\hline BDKRB1 & Bradykinin receptor $\mathrm{B} 1$ & NM_000710 & 3.794 & 0.0027 & 4.178 & 0.0365 \\
\hline ACAS2L & $\begin{array}{l}\text { Acetyl-coenzyme A synthetase } 2 \\
\text { (AMP forming)-like }\end{array}$ & AK024396 & 3.784 & 0.0001 & 0.377 & 0.0030 \\
\hline NXF2 & Nuclear RNA export factor 2 & NM_017809 & 3.705 & 0.0088 & 0.171 & 0.0106 \\
\hline PSMB8 & $\begin{array}{l}\text { Proteasome (prosome, macropain) subunit, } \\
\text { b-type, } 8 \text { (large multifunct. Prot. } 7 \text { ) }\end{array}$ & NM_004159 & 3.690 & 0.0058 & 0.357 & 0.0333 \\
\hline PLK & Polo-like kinase (Drosophila) & NM_005030 & 3.192 & 0.0273 & 0.382 & 0.0254 \\
\hline HCK & Hemopoietic cell kinase & NM_002110 & 3.172 & 0.0003 & 0.312 & 0.0207 \\
\hline GPRC5B & G protein-coupled receptor, $(\mathrm{C} 1 \mathrm{~B})$ & NM_016235 & 3.124 & 0.0214 & 3.544 & 0.0241 \\
\hline HLA-E & Major histocompatibility complex, class I, E & NM_005516 & 3.123 & 0.0084 & 0.277 & 0.0387 \\
\hline LOC51133 & NY-REN-45 antigen & NM_016121 & 3.089 & 0.0029 & 3.284 & 0.0054 \\
\hline FACVL1 & $\begin{array}{l}\text { Fatty-acid-coenzyme A ligase, } \\
\text { very long-chain } 1\end{array}$ & NM_003645 & 2.842 & 0.0087 & 0.303 & 0.0401 \\
\hline RHEB2 & Ras homolog enriched in brain 2 & NM_005614 & 2.717 & 0.0114 & 0.456 & 0.0495 \\
\hline PRKAG3 & $\begin{array}{l}\text { Protein kinase, AMP-activated, } \\
\gamma 3 \text { non-catalytic subunit }\end{array}$ & NM_017431 & 2.715 & 0.0040 & 0.261 & 0.0023 \\
\hline COL4A6 & Collagen, type IV, $\alpha 6$ & NM_033641 & 2.703 & 0.0081 & 0.350 & 0.0227 \\
\hline UGT8 & $\begin{array}{l}\text { UDP glycosyltransferase } 8 \\
\text { (UDP-galactose ceramide galactosyltransf.) }\end{array}$ & NM_003360 & 2.419 & 0.0034 & 0.474 & 0.0068 \\
\hline HAL & Histidine ammonia-lyase & NM_002108 & 2.291 & 0.0009 & 0.287 & 0.0468 \\
\hline GRO1 & $\begin{array}{l}\text { GRO1 oncogene (melanoma growth } \\
\text { stimulating activity, } \alpha \text { ) }\end{array}$ & NM_001511 & 2.258 & 0.0012 & 0.447 & 0.0419 \\
\hline LOC51030 & CGI-148 protein & NM_016078 & 2.237 & 0.0014 & 4.225 & 0.0348 \\
\hline CHRNA5 & Cholinergic receptor, nicotinic, $\alpha$ polypept. 5 & NM_000745 & 2.225 & 0.0048 & 0.381 & 0.0292 \\
\hline SCTR & Secretin receptor & NM_002980 & 2.198 & 0.0011 & 0.277 & 0.0017 \\
\hline RANBP3 & RAN binding protein 3 & NM_003624 & 2.158 & 0.0242 & 0.364 & 0.0120 \\
\hline RANGAP1 & Ran GTPase activating protein 1 & AB058738 & 2.156 & 0.0017 & 0.452 & 0.0178 \\
\hline C1S & Complement component $1, \mathrm{~s}$ subcomp. & NM_001734 & 2.143 & 0.0260 & 0.240 & 0.0078 \\
\hline ACATN & Acetyl-coenzyme A transporter & NM_004733 & 2.065 & 0.0084 & 2.064 & 0.0495 \\
\hline TST & Thiosulfate sulfurtransferase (rhodanese) & NM_003312 & 2.059 & 0.0287 & 0.447 & 0.0227 \\
\hline TNRC4 & Trinucleotide repeat containing 4 & NM_007185 & 2.035 & 0.0046 & 0.408 & 0.0145 \\
\hline
\end{tabular}

(GO) terms with a significant accumulation of changed genes on all levels of the hierarchical GO tree structure and revealed far more than 100 terms significantly affected by the applied cell treatment. In the gene ontology 'biological process' we found 54 terms, in 'molecular function' 49 terms and in 'cellular component' 14 terms. To further concentrate these results we combined subsequent terms of subcategories under the highest parent GO term, which was affected significantly and could detect a couple of main fields. Fig. 2 shows the main GO terms of the different categories ranked according to the number of subsequent terms that could be assigned to them.

The category 'biological process' was reduced to 11 main terms (Fig. 2). The highest ranked terms 'response to stimulus' and 'organic acid metabolism' subsumed 16 subsequent terms, including 17 and 6 co-regulated genes, respectively. The term 'oxygen and reactive oxygen species metabolism', which was highly significantly affected $(\mathrm{p}=0.0007)$, was partly involved in the term 'response to stimulus'. The total number of involved terms shows the great dimension of the 'response to stimulus' term. Certainly, not all of its aspects are influenced by the applied cell treatment, but the number of 17 co-regulated genes indicates a substantial involvement of the p38MAPK pathway in this biological process, playing a pivotal role in the context of inflammation. Therefore, these two terms were further analyzed in the next paragraph as an example of detailed interpretations of GO term results.

In the category 'molecular function', 7 main terms were identified (Fig. 2). The highest ranked parent term 'ligase activity' included 15 of 18 possible child terms and involved 5 regulated genes. 


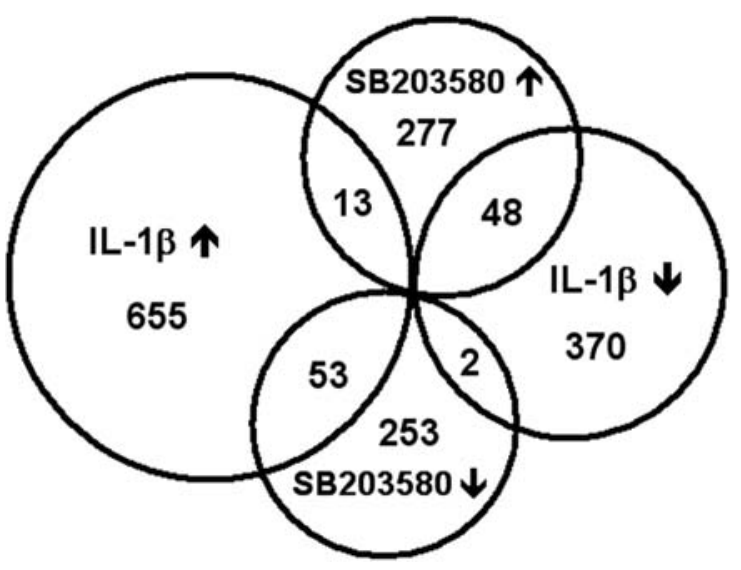

Figure 1. Number of all IL-1ß- and SB203580-regulated genes found in the microarray analysis. Arrows indicate up- and down-regulation in comparison to reference cells. IL-1ß-stimulated cells were compared to untreated cells, SB203580-treated and IL-1B-stimulated cells were compared to stimulated cells without inhibition.

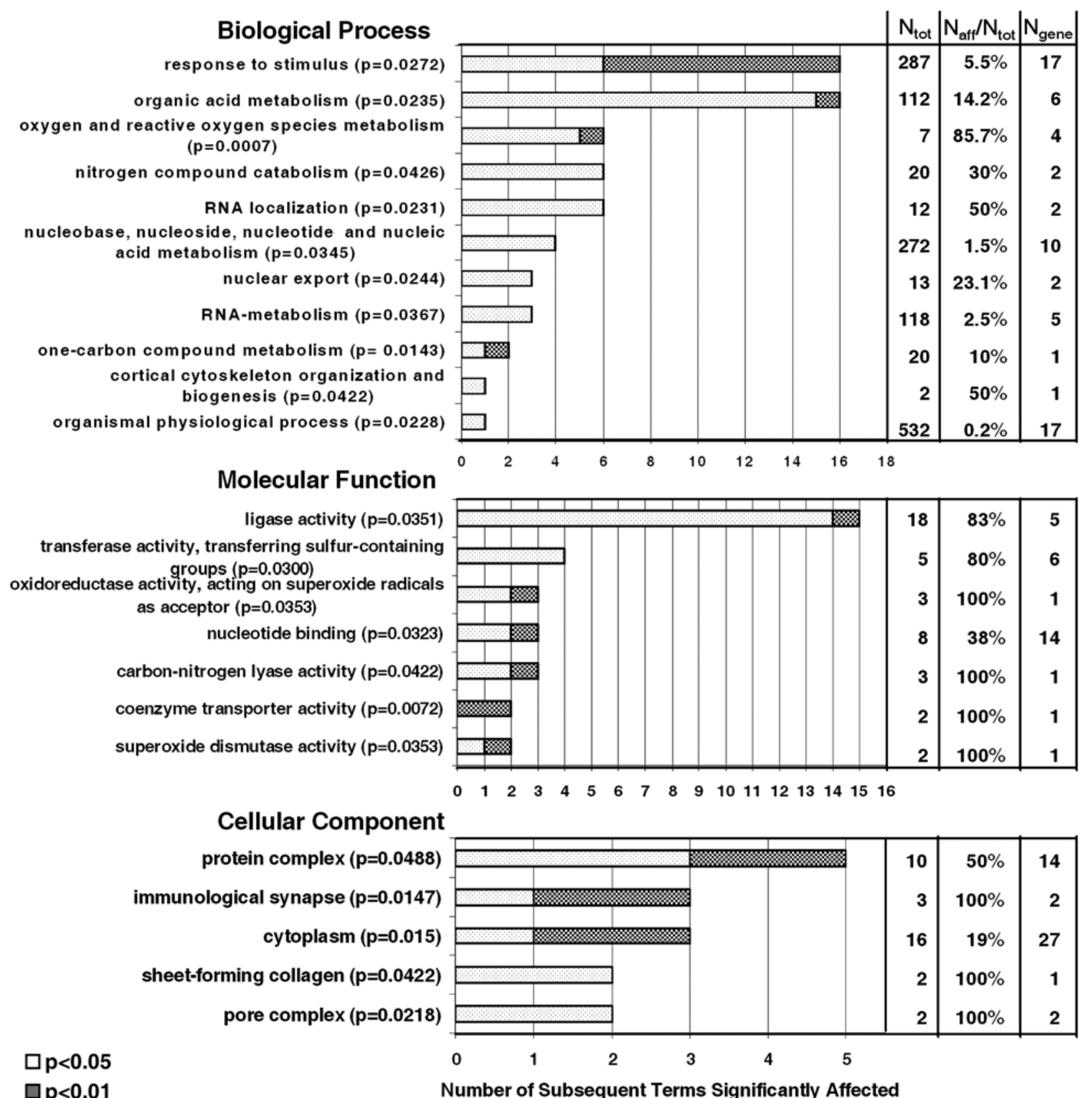

Figure 2. Main GO terms of the different GO categories that were significantly enriched in genes co-regulated by IL-1ß and SB203580. The main terms are ranked according to the number of affected child terms which could be assigned to them. The p-value of the main terms is given in parentheses. The affiliated table shows the total number of possible child terms $\left(\mathrm{N}_{\text {tot }}\right)$, the percentage of affected to total child terms ( $\left.\mathrm{N}_{\text {aff }} / \mathrm{N}_{\text {tot }}\right)$ and the number of involved co-regulated genes $\left(\mathrm{N}_{\text {gene }}\right)$. 


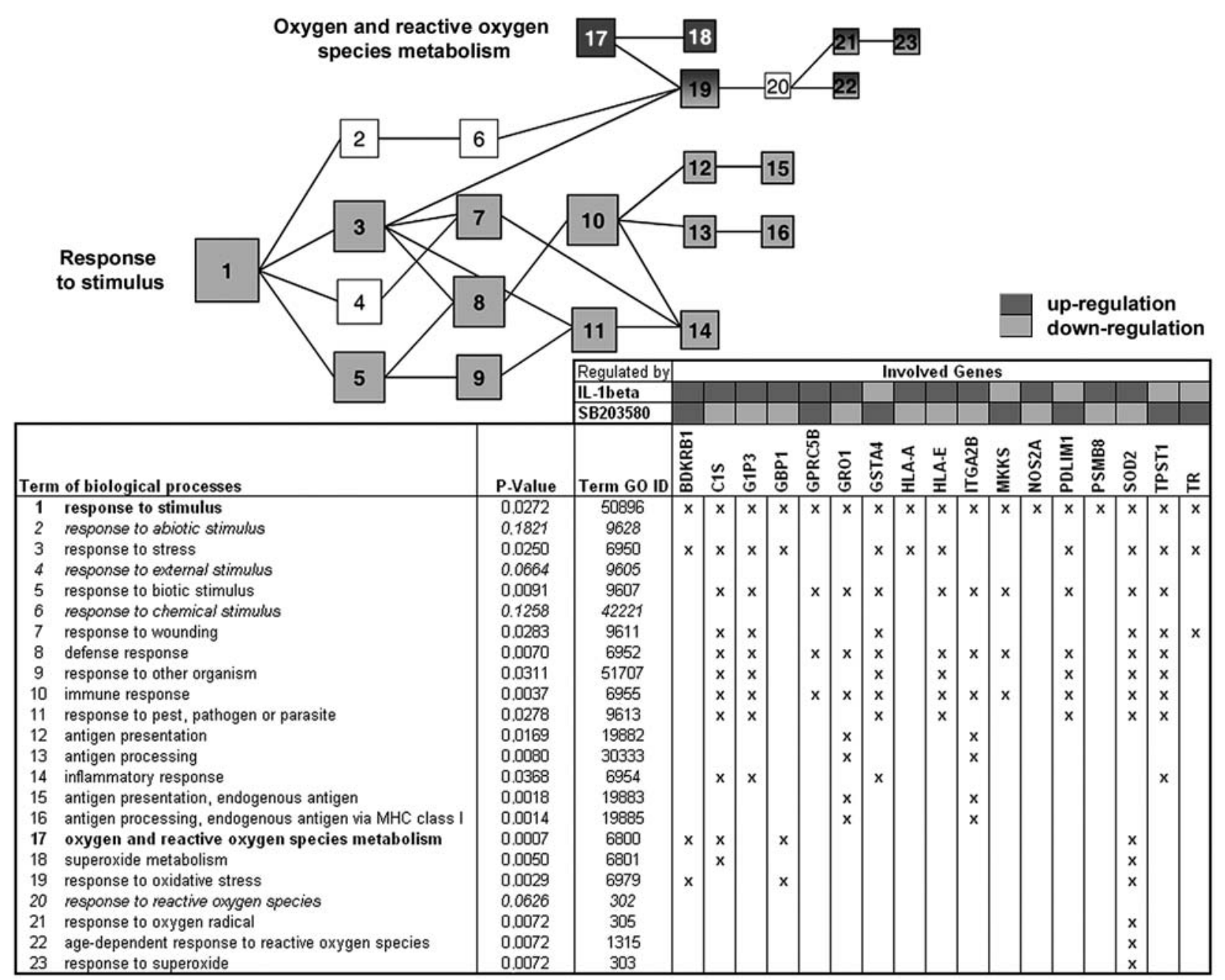

Figure 3. Directed acyclic graph (DAG) representation of the terms 'response to stimulus' and 'oxygen and reactive oxygen species metabolism' with all affected child terms and involved regulated genes. The associated terms that were not significantly affected are in italics. The p-values, the identification numbers (GO ID) of the terms and the direction of the gene regulation by IL-1ß and SB203580 are provided.

Beside the other listed main terms in 'molecular functions' of Fig. 2, 17 further GO terms of this category were significantly affected but could not be summarized in parent terms. These single terms were not ranked in the plot shown in Fig. 2.

The category 'cellular component' comprised 5 main terms. The highest ranked main term 'protein complex' subsumed 5 of 10 possible child terms that were significantly enriched in regulated genes.

Detailed analysis of two GO terms. As an example, the terms 'response to stimulus' and 'oxygen and reactive oxygen species metabolism' were assembled in a directed acyclic graph (DAG) representation in Fig. 3. All enriched child terms, the involved genes and their regulation by IL-1ß and SB203580 are given. A detailed analysis of the function of the according proteins and the direction of regulation helps to interpret the cellular response. The term 'oxygen and reactive oxygen species metabolism', which is also partly involved in the 'response to stimulus' term, involved the 4 genes Nos $2 a$, Pdlim1, Sod 2 and Tr. Subsuming all given subterms, the term 'response to stimulus' involved 17 different genes, of which 12 genes were up-regulated and 5 genes were down-regulated by IL-1ß. In 15 cases, SB203580 counteracted these modulations, whereas for the IL-1ß-stimulated genes $B d k r b 1$ and Gprc5b, the inhibition of p38MAPK further enhanced gene expression. Many of these genes are known to play a role in cartilage biology or even the pathogenesis of arthritis and will be considered in the discussion.

Pathway and oncogene analysis of all SB203580-regulated genes. For therapeutical interventions in cellular processes, the question of unexpected effects is an important issue. We, therefore, further analyzed all 646 genes that were regulated by the p38MAPK inhibitor SB203580 irrespective of an IL-1ß regulation. A GoMiner pathway analysis in the category 'biological process' of the list of SB203580-regulated genes revealed a significant enrichment of regulated genes in 41 different GO terms. Table II gives 6 main terms subsuming 24 significantly affected child terms. Just as for the GoMiner pathway analysis of co-regulated genes, we found the terms 'oxygen and reactive oxygen species metabolism' and 
Table II. GO terms of the category 'biological process' significantly enriched in SB203580-regulated genes. ${ }^{\text {a }}$

\begin{tabular}{|c|c|c|c|}
\hline Main term & p-value & Number of affected child terms & Number of involved genes \\
\hline Gas transport & 0.0491 & 2 & 2 \\
\hline Macromolecule biosynthesis & 0.0258 & 3 & 15 \\
\hline Negative regulation of vasodilation & 0.0330 & 1 & 1 \\
\hline Oxygen and reactive oxygen species metabolism & 0.0393 & 2 & 5 \\
\hline Positive regulation of oxidoreductase activity & 0.0330 & 2 & 1 \\
\hline Response to stimulus & 0.0050 & 14 & 39 \\
\hline$\rightarrow$ Subgroup: regulation of blood coagulation & 0.0411 & 2 & 2 \\
\hline
\end{tabular}

${ }^{a}$ Affected child terms are subsumed.

Table III. List of SB203580-regulated genes that are also listed in the Tumor Gene Family of Databases, their function in tumor biology and the effect of the regulation on cancer development.

\begin{tabular}{lclcc}
\hline Gene symbol & $\begin{array}{c}\text { Regulation by } \\
\text { SB203580 }\end{array}$ & \multicolumn{1}{c}{ Function in tumor biology } & $\begin{array}{c}\text { Accession no. } \\
\text { OMIM }^{\mathrm{a}}\end{array}$ & $\begin{array}{c}\text { Predicted effect of } \\
\text { SB203580 on } \\
\text { cancer development }\end{array}$ \\
\hline CDC25B & Down & $\begin{array}{l}\text { Overexpressed in breast cancer, upregulates } \\
\text { cyclin-dependent kinases }\end{array}$ & 116949 & Repression \\
GRO1 & Down & Chemokine, overexpressed in ovarian cancer & 155730 & Repression \\
HCK & Down & Expression prominent in cells of myeloid lineage & 142370 & Repression \\
IL2RA & Down & Cytokine receptor, oncogene family member, & 147730 & Repression \\
JUN & & activation of Raf-1 & 165160 & Repression \\
MDM2 & Down & Transcription factor, proto-oncogene & 164785 & Enhancement \\
MPL & Up & Oncogene, major regulator of the tumor suppressor p53 & 159530 & Repression \\
NF2 & Down & Cytokine-receptor, oncogene & 101000 & Repression \\
NME1 & Up & Tumor suppressor & 156490 & Repression \\
SOS1 & Up & Metastasis-suppressor gene & 182530 & Repression \\
TCF3 & Down & May act as a positive regulator of RAS & 147141 & Repression \\
& Down & Transcription factor, PRL-fusion protein may contribute & & \multicolumn{1}{c}{ to } \\
\hline
\end{tabular}

aAccession number for the 'Online Mendelian Inheritance in Man' (OMIM).

\footnotetext{
'response to stimulus' significantly involved. The subgroup 'regulation of blood coagulation' may be surprising in the context of chondrocytes concerning unexpected effects and is additionally indicated. It involves the regulation of plasma kallikrein gene expression, an activator of fibrinolysis. Other alarming terms like apoptosis were not significantly affected by $\mathrm{p} 38 \mathrm{MAPK}$ inhibition.

Further data interpretation included a comparison of the SB203580-regulated genes with a list of more than 300 genes that are known to play a role in tumor biology [Tumor Gene Family of Databases (11)]. Among the 646 regulated genes, we found 11 matches listed in Table III. The regulation by p38MAPK inhibition, the gene functions in tumor context and the OMIM Accession nos. (12) are indicated. Except for Mdm2 regulation (Table III), SB203580 regulation predicts a cancer repressive effect.
}

\section{Discussion}

The whole human genome microarray analysis of IL-1ß- and p38MAPK inhibitor-treated chondrocytes revealed a huge number of genes whose expression was affected by the cell treatment. Many typical effects previously described in the literature were confirmed (6). Comparing the effects of IL-1ß and SB203580, we found that more than $80 \%$ of the SB203580-regulated genes were unaffected by IL-1ß pointing to the importance of $\mathrm{p} 38 \mathrm{MAPK}$ in many different pathways (13).

The condensation of these results in a GoMiner Pathway Analysis of co-regulated genes showed a number of mainly affected fields in the different GO categories. Especially the terms 'response to stimulus' and 'oxygen and reactive oxygen species metabolism' of the category 'biological process' 
were predominantly involved and analyzed in detail (Fig. 3). The regulation of the genes involved in oxygen metabolism causes a consistent effect. The up-regulation of Nos $2 a$ (nitric oxide synthase $2 \mathrm{~A}$ ) and the down-regulation of $\operatorname{Tr}$ (thioredoxin reductase) by IL-1ß both aggravate the oxidative stress in the cell by enhanced synthesis of NO and by reduced regeneration of the antioxidant thioredoxin (14-16). The upregulation of $\operatorname{Sod} 2$ (superoxide dismutase 2) counteracts this process as it is a protector from ROS-mediated cell damage (17). The effect of p38MAPK inhibition by SB203580 treatment is directly opposed to the stimulation effect. This means a lesser extent of oxygen species formation but also a lower protection by SOD2.

For some of these factors, a role in cartilage and joint biology is already described and may shed light on their function in inflammatory processes. The already described events in oxygen species metabolism by Nos $2 a$ and $T r$ regulation may contribute to inflammation in joint diseases (17). The down-regulation of the glutathione S-transferase gene Gsta4 can also be added to this metabolism field as this enzyme is involved in cellular detoxification mechanisms of electrophile compounds like hydroperoxides (18). Recently, Vaillancourt et al found that GSTA4-4 expression is critically important for cellular defense against oxidative stress-induced cell death in osteoarthritic cartilage (19).

The up-regulation of Hla-a, assigned to the term 'response to stimulus', is somehow surprising in the cartilage context. HLA-A, a major histocompatibility antigen class I, is actually expressed on chondrocytes (20) and normally responsible for antigen presentation of endogenous peptides. In tissues not primarily involved in immune response, possible roles in other functions such as immune surveillance for the development of tumor cells are discussed (20). Notably, an association of the HLA system and osteoarthritis of the hand was suggested previously (21).

The Bradykinin receptor BDKRB1 is a G protein-coupled receptor and is co-induced with COX2 and NOS2A by inflammatory stimuli (22). It was shown that this receptor mediates effects of the inflammatory peptide bradykinin in porcine chondrocytes like $\mathrm{PGE}_{2}$ generation (23).

The serine protease $\mathrm{C} 1 \mathrm{~s}$ is part of the first complement complex and initiates the complement cascade which actually is a central component in host defense. More important in the cartilage context may be the report of a collagenase activity of $\mathrm{C} 1 \mathrm{~s}$ (24). A role of $\mathrm{C} 1 \mathrm{~s}$ was also suggested in degenerative joint diseases (25).

Overall, the detailed interpretation of IL-1B- and SB203580-induced regulations of genes assigned to the term 'response to stimulus', shows a strong anti-inflammatory effect of p38MAPK inhibition in versatile fields of cellular response. One has to keep in mind, however, that individual results have to be verified with a larger sample size. Another point to be taken into account is an inhibitory effect of SB203580 on other kinases, although weaker than on p38a (3), that could additionally affect the gene expression profile.

The GO category 'molecular function' also revealed a predominantly affected term called 'ligase activity'. This term comprises enzymes of EC class 6, that catalyze mainly ligations of nucleotide fragments. These reactions are most important in DNA replication and repair which was also necessary in cells that suffer from DNA damage. Such damage can be caused by reactive oxygen species (ROS) and NO (15), induced by cytokines, for example. This reflects the conditions in our in vitro cell culture model. Probably, the chondrocytes initiate protective processes like DNA repair mechanisms (26) for which ligase activity is an important function (27). A second aspect of ligase activity is provided by some of the subsumed child terms that represent aminoacyltRNA ligase functions. Enzymes of this term are not only housekeeping genes involved in protein synthesis. New findings have shown that they play non-catalytic roles in diverse biological processes and in signal transduction (28).

The question regarding unexpected effects of SB203580 was addressed with the pathway analysis of all inhibitorregulated genes. Among the listed terms, oxygen metabolism might be a critical point concerning unwanted effects of SB203580. Most of the genes involved were already discussed in the previous passage and revealed a rather attenuating effect of SB203580 on oxidative stress in the cell. The term 'regulation of blood coagulation', mainly reflects the regulation of plasma kallikrein gene expression. In fact, an association of kallikrein and the fibrinolytic system with cartilage degradation has been suggested $(29,30)$. Other alarming terms like apoptosis are not significantly affected by $\mathrm{p} 38 \mathrm{MAPK}$ inhibition. Recent findings indicated that genetic inhibition throughout the lifespan leads to worsened osteoarthritis in adult mice (5). Therefore, the timing of the therapeutical application of p38 inhibitors was considered to be critical. Our results do not provide an indication that short-term exposure of chondrocytes to SB203580 implicate important alarming effects.

Similarly, the search for oncogene regulation in chondrocytes by inhibitor treatment revealed a rather cancer repressing effect of SB203580. This is in agreement with reports of cytotoxicity enhancing effect of p38MAPK inhibition in myeloma cells (31).

In summary, we present initial data of a genome-wide analysis of p38MAPK inhibition in an inflammation model of human chondrocytes. Besides well-described effects we found new aspects of cellular reactions in response to p38MAPK inhibition such as alterations in 'ligase activity'. Additional information on the expected involvement of biological areas such as 'response to stimulus' or 'reactive oxygen species' further contributes to our fragmentary knowledge on these cellular processes in chondrocytes which has been based on primary target genes so far.

The great number of SB203580-regulated genes further emphasizes the pivotal role of this signaling pathway in human chondrocytes which is not restricted to IL- $1 \beta$ induction. Finally, a whole genome array is a valuable tool in unravelling unexpected effects which may contradict a therapeutic application. In our analyses, we found no markedly alarming gene regulation predicting, for example, chondrocyte apoptosis which might aggravate joint degeneration.

\section{Acknowledgements}

The authors would like to thank Ratiopharm Ulm for supporting this study and providing SB203580 and Dr K. Holzmann from 
the Microarray-Facility Ulm for his support in the chip analysis.

\section{References}

1. Berenbaum F: Signaling transduction: target in osteoarthritis. Curr Opin Rheumatol 16: 616-622, 2004.

2. Fernandes JC, Martel-Pelletier J and Pelletier JP: The role of cytokines in osteoarthritis pathophysiology. Biorheology 39: 237-246, 2002.

3. Lee JC, Kumar S, Griswold DE, Underwood DC, Votta BJ and Adams JL: Inhibition of p38 MAP kinase as a therapeutic strategy. Immunopharmacology 47: 185-201, 2000.

4. Lee JC, Laydon JT, McDonnell PC, Gallagher TF, Kumar S, Green D, McNulty D, Blumenthal MJ, Keys JR, Land vatter SW, Strickler JE, McLaughlin MM, Siemens IR, Fisher SM, Livi GP, White JR, Adams JL and Young PR: A protein kinase involved in the regulation of inflammatory cytokine biosynthesis. Nature 372: 739-746, 1994

5. Namdari S, Wei L, Moore D and Chen Q: Reduced limb length and worsened osteoarthritis in adult mice after genetic inhibition of p38 MAP kinase activity in cartilage. Arthritis Rheum 58: 3520-3529, 2008.

6. Joos H, Albrecht W, Laufer S, Reichel H and Brenner RE: IL-1 beta regulates FHL2 and other cytoskeleton-related genes in human chondrocytes. Mol Med 14: 150-159, 2008.

7. Buchholz M, Braun M, Heidenblut A, Kestler HA, Kloeppel G, Schmiegel W, Hahn SA, Luettges J and Gress TM: Transcriptome analysis of microdissected pancreatic intraepithelial neoplastic lesions. Oncogene 24: 6626-6636, 2005.

8. Zeeberg BR, Feng W, Wang G, Wang MD, Fojo AT, Sunshine M, Narasimhan S, Kane DW, Reinhold WC, Lababidi S, Bussey KJ, Riss J, Barrett JC and Weinstein JN: GoMiner: a resource for biological interpretation of genomic and proteomic data. Genome Biol 4: R28, 2003.

9. GoMiner (database on the Internet): http://discover.nci.nih. gov/gominer/. cited. Available from: http://discover.nci.nih.gov/ gominer/.

10. Smyth GK: Linear models and empirical bayes methods for assessing differential expression in microarray experiments. Stat Appl Genet Mol Biol 3: Article 3, 2004.

11. The Tumor Gene Family of Databases (database on the Internet). http://www tumor-gene.org/. cited. Available from: http://www.tumor-gene.org/.

12. OMIM [database on the Internet]. http://www.ncbi.nlm.nih. gov/sites/entrez?db=omim. cited. Available from: http://www. ncbi.nlm.nih. gov/sites/entrez?db=omim.

13. Schett G, Zwerina J and Firestein G: The p38 mitogen-activated protein kinase (MAPK) pathway in rheumatoid arthritis. Ann Rheum Dis 67: 909-916, 2008.

14. Wang $\mathrm{H}$, Wang $\mathrm{Z}$, Chen $\mathrm{J}$ and $\mathrm{Wu} \mathrm{J}$ : Apoptosis induced by NO via phosphorylation of p38 MAPK that stimulates NF-kappaB, p53 and caspase- 3 activation in rabbit articular chondrocytes. Cell Biol Int 31: 1027-1035, 2007.

15. Wu GJ, Chen TG, Chang HC, Chiu WT, Chang CC and Chen RM: Nitric oxide from both exogenous and endogenous sources activates mitochondria-dependent events and induces insults to human chondrocytes. J Cell Biochem 101: 1520-1531, 2007.
16. Lemarechal H, Allanore Y, Chenevier-Gobeaux C, Ekindjian OG, Kahan A and Borderie D: High redox thioredoxin but low thioredoxin reductase activities in the serum of patients with rheumatoid arthritis. Clin Chim Acta 367: 156-161, 2006.

17. Afonso V, Champy R, Mitrovic D, Collin P and Lomri A: Reactive oxygen species and superoxide dismutases: role in joint diseases. Joint Bone Spine 74: 324-329, 2007.

18. Hayes JD, Flanagan JU and Jowsey IR: Glutathione transferases. Annu Rev Pharmacol Toxicol 45: 51-88, 2005.

19. Vaillancourt F, Fahmi H, Shi Q, Lavigne P, Ranger P, Fernandes JC and Benderdour M: 4-Hydroxynonenal induces apoptosis in human osteoarthritic chondrocytes: the protective role of glutathione-S-transferase. Arthritis Res Ther 10: R107, 2008.

20. Lance EM, Kimura LH and Manibog CN: The expression of major histocompatibility antigens on human articular chondrocytes. Clin Orthop Relat Res 291: 266-282, 1993.

21. Merlotti D, Santacroce C, Gennari L, Geraci S, Acquafredda V, Conti T, Bargagli G, Canto ND, Biagi F, Gennari C and Giordano N: HLA antigens and primary osteoarthritis of the hand. J Rheumatol 30: 1298-1304, 2003.

22. Calixto JB, Medeiros R, Fernandes ES, Ferreira J, Cabrini DA and Campos MM: Kinin B1 receptors: key G-protein-coupled receptors and their role in inflammatory and painful processes. Br J Pharmacol 143: 803-818, 2004.

23. Benton HP, Jackson TR and Hanley MR: Identification of a novel inflammatory stimulant of chondrocytes. Early events in cell activation by bradykinin receptors on pig articular chondrocytes. Biochem J 258: 861-867, 1989.

24. Yamaguchi K, Sakiyama H, Matsumoto M, Moriya H and Sakiyama S: Degradation of type I and II collagen by human activated C1-s. FEBS Lett 268: 206-208, 1990.

25. Nakagawa K, Sakiyama H, Tsuchida T, Yamaguchi K, Toyoguchi T, Masuda R and Moriya H: Complement C1s activation in degenerating articular cartilage of rheumatoid arthritis patients: immunohistochemical studies with an active form specific antibody. Ann Rheum Dis 58: 175-181, 1999.

26. Rosales AL, Cunningham JM, Bone AJ, Green IC and Green MH: Repair of cytokine-induced DNA damage in cultured rat islets of Langerhans. Free Radic Res 38: 665-674, 2004.

27. Hegde ML, Hazra TK and Mitra S: Early steps in the DNA base excision/single-strand interruption repair pathway in mammalian cells. Cell Res 18: 27-47, 2008.

28. Lee SW, Cho BH, Park SG and Kim S: Aminoacyl-tRNA synthetase complexes: beyond translation. J Cell Sci 117: 3725-3734, 2004.

29. Cruwys SC, Davies DE and Pettipher ER: Co-operation between interleukin-1 and the fibrinolytic system in the degradation of collagen by articular chondrocytes. Br J Pharmacol 100: 631-635, 1990

30. Suzuki M, Ito A, Mori Y, Hayashi Y and Matsuta K: Kallikrein in synovial fluid with rheumatoid arthritis. Biochem Med Metab Biol 37: 177-183, 1987

31. Wen J, Cheng HY, Feng Y, Rice L, Liu S, Mo A, Huang J, Zu Y, Ballon DJ and Chang CC: P38 MAPK inhibition enhancing ATO-induced cytotoxicity against multiple myeloma cells. Br J Haematol 140: 169-180, 2008. 